УДК 631.458:632.125

К ВОПРОСУ ОПЕРАТИВНОГО КОНТРОЛЯ ПОЧВЕННОГО

ПЛОДОРОДИЯ ПРИ ВЫРАЩИВАНИИ СЕЛЬСКОХОЗЯЙСТВЕННЫХ КУЛЬТУР НА ЮГЕ ДАЛЬНЕГО ВОСТОКА

\author{
Мухина Н.В., Суржик М.М. \\ ФГБОУ ВО «Приморская государственная сельскохозяйственная академия», Уссурийск, \\ e-mail:muxina-847@mail.ru,mariams2003@mail.ru
}

\begin{abstract}
Мониторинг почвенного плодородия на юге Дальнего Востока является актуальной задачей в связи с интенсивным развитием земледелия в последнее десятилетие. Это обусловлено специфическими условиями почвообразования и особенностями ведения сельскохозяйственного производства в области растениеводства, такими как несоблюдение научно обоснованных севооборотов и недостаточное внесение удобрений в почву. Производство зерна сои и кукурузы не является весьма востребованным в регионе, но создает риски для деградации почв. Целью исследования является изучение изменений основных параметров почвенного плодородия на основе мониторинга реперных площадок. Объектом исследования служат почвы пахотных угодий на территории сельскохозяйственных предприятий Приморского края. Использованы общепринятые методики. В статье показаны изменения основных показателей плодородия почв в пределах заложенных реперных площадок. За 3 года, в которые проводились исследования, на ряде площадок отмечено снижение показателей почвенного плодородия. Особенно это коснулось содержания гумуса, резкое снижение которого обусловлено совокупностью природных и антропогенных факторов. Содержание гумуса понизилось на 1-15\%. Причинами этого послужили интенсивные ливневые дожди, выпавшие в период вегетации растений, и несоблюдение агротехники выращивания растений в условиях эрозионной опасности земель. Содержание подвижного фосфора и обменного калия снизилось не так резко. Кислотность почв изменилась в сторону увеличения на большинстве реперных площадок. На некоторых реперных площадках отмечено устойчивое содержание либо повышение показателей почвенного плодородия, что зависит также от типов почв и их местоположения относительно рельефа. Мониторинг почв на реперных площадках позволит производить своевременный контроль за изменением показателей почвенного плодородия. Это может явиться основой для расчета количества удобрений и проведения мероприятий, предотвращающих деградацию пахотных угодий.
\end{abstract}

Ключевые слова: Дальний Восток, Приморский край, почвы, оперативный контроль, мониторинг, плодородие

\title{
REVISITING THE OPERATIONAL CONTROL OF SOIL FERTILITY FOR GROWING AGRICULTURAL CROPS IN THE SOUTH OF THE FAR EAST
}

Mukhina N.V., Surzhik M.M.

\author{
Primorye State Agricultural Academy,Ussuriisk,e-mail:muxina-847@mail.ru,mariams2003@mail.ru
}

Monitoring of the soil fertility in the Southern Part of the Far East is an actual task for the intensive agricultural development. This is due to the specific conditions of soil formation and the peculiarities of agricultural production in the field of crop production, such as non-compliance with science-based crop rotations and insufficient fertilization in the soil. The production of soybeans and corn is highly demanded in the region, but it creates risks for the occurrence of soil degradation. The aim of the current research is to study changes in the basic parameters of soil fertility. It based on monitoring of bench-mark sites. Materials and methods. The object of study is the arable soils in the territory of agricultural enterprises of Primorye region. Conventional techniques used. Results. The article shows the changes in the main indicators of soil fertility within the established reference areas. Over the 3 years in which research was conducted, a decrease in soil fertility indicators was observed on a number of sites. This especially affected the humus content, a sharp decrease in which is due to a combination of natural and anthropogenic factors. The humus content decreased by $1-15 \%$. The critical decrease in humus was influenced by intense rain showers that fell during the growing season, and non-compliance with the agro technology of growing plants in conditions of erosion risk. The content of labile phosphorus and exchangeable potassium decreased not so sharply. Soil acidity has changed upward on most reference sites. On some bench-mark sites, a stable content, or an increase in soil fertility indicators, is noted, which also depends on the types of soils and their location relative to the relief. Conclusions. Soil monitoring at bench-mark sites will allow timely monitoring of changes in soil fertility indicators. This can be the basis for calculating the amount of fertilizer and carrying out measures to prevent the degradation of arable land.

Keywords: Far East, Primorye region, soils, operational control, monitoring, fertility

В последние годы на юге Дальнего Востока активно развивается земледелие, что связано с высокой востребованностью продукции сельского хозяйства как на внутреннем рынке, так и в странах АзиатскоТихоокеанского региона. В связи с этим увеличивается площадь пашни, находящаяся в интенсивном использовании. Однако большинство почв юга Дальнего Востока не обладают высоким естественным плодородием. Они уязвимы в отношении процессов эрозии и деградации, вызываемых как естественными причинами, так и высокой антропогенной нагрузкой. Большая часть почв юга Дальнего Востока обладает общим недостатком, существенным с агро- 
номической точки зрения. Наиболее ценные пахотнопригодные почвы равнинной части в естественном состоянии обладают маломощным гумусовым горизонтом, высокой обменной и гидролитической кислотностью и низким содержанием подвижных элементов питания, особенно это касается фосфора $[1,2]$. В условиях высокой интенсивности использования пашни существует проблема своевременного слежения за изменением показателей плодородия почв. Наблюдается общее снижение содержания органического вещества и основных элементов питания в пахотных почвах, что является следствием несоблюдения севооборотов и недостаточного удобрения почвы в большинстве сельскохозяйственных предприятий $[3,4]$. В этой ситуации мониторинг почвенного плодородия необходимо проводить регулярно на всех интенсивно используемых пахотных землях. Это позволит своевременно реагировать на изменение показателей плодородия почвы, рационально планировать мероприятия по недопущению деградации почв. Поэтому оперативный мониторинг основных показателей почвенного плодородия становится одним из актуальных вопросов исследования. Для решения этой проблемы важным является налаживание системы контроля почвенного плодородия на уровне сельскохозяйственных предприятий юга Дальнего Востока.

Целью исследования является изучение изменений основных параметров почвенного плодородия в различных сельскохозяйственных предприятиях юга Дальнего Востока за период интенсивного выращивания сельскохозяйственных культур (сои и кукурузы) на основе мониторинга реперных площадок.

Научная новизна исследования заключается в выявлении изменений плодородия интенсивно используемых почв в различных почвенно-ландшафтных условиях, а практическая новизна состоит в организации регулярных наблюдений за изменениями показателей почвенного плодородия.

\section{Материалы и методы исследования}

Объектом исследования являются почвы пахотных угодий на территории сельскохозяйственных предприятий, специализирующихся на выращивании сои и кукурузы на зерно, в Октябрьском, Михайловском, Пограничном, Черниговском муниципальных районах, Уссурийском и Артемовском городских округах Приморского края (рис. 1). Земли в указанных райо- нах являются наиболее интенсивно используемыми, поскольку, во-первых, находятся в наиболее удобных условиях в отношении рельефа и почв, и, во-вторых, расположены в непосредственной близости от пунктов переработки и сбыта продукции сельского хозяйства. Исследования изменений почвенного плодородия проводились в 2012, 2014 и 2017 гг.

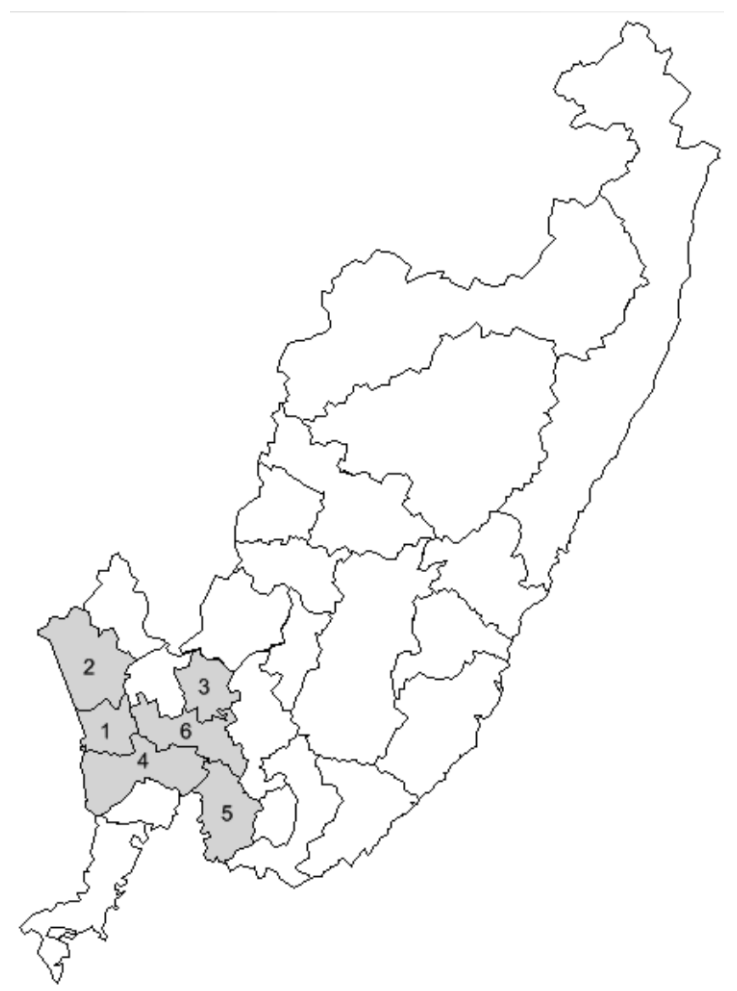

Рис. 1. Местоположение муниципальных районов Приморского края, в которых расположены реперные площчадки: 1 - Октябрьский, 2-Пограничный, 3 - Черниговский,

4 - Уссурийский ГО, 5 - Артемовский ГО и Шкотовский, 6-Михайловский

Исследования опираются на метод организации мониторинга, основанный на периодических наблюдениях на реперных площадках [5]. На землях сельскохозяйственных предприятий были выделены площадки с учетом почвенно-экологического районирования и варьирования свойств почв. Границы площадок закреплены на территории реперными знаками с точными координатами. Исследовался пахотный горизонт почв. Почвенные пробы отбирались весной с помощью тростевого бура по 36 уколов для каждой реперной площадки. Из отобранных проб готовились смешанные образцы почв. 


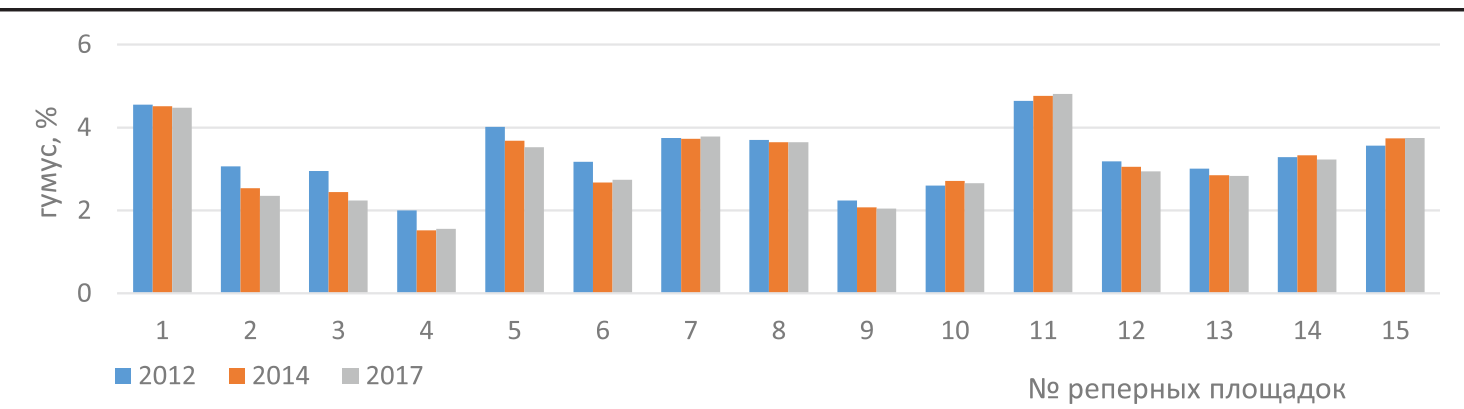

Pис. 2. Содержание гумуса (\%) на реперных площуадках в 2012, 2014 и 2017 г2.

Почвы обследовались на содержание гумуса, подвижного фосфора, обменного калия, величины обменной кислотности по солевой вытяжке в пахотном слое по общепринятым методикам [6-8].

\section{Результаты исследования и их обсуждение}

Приморский край находится в особых климатических условиях, носящих умеренно-муссонные черты с признаками континентальности в центральной его части. Особенности климата, такие как холодная и сырая весна и ливневые дожди в летний период, чередующийся с сухой осенью и малоснежной зимой, формируют специфические условия почвообразования. Интенсивное антропогенное воздействие на почвы равнин Приморья вызывает необходимость принятия мер к систематическому контролю их агрохимического состояния [5].

Контроль за состоянием почв опирается на законодательно установленные критерии снижения почвенного плодородия [9]. Для оценки почвенного плодородия согласно этому документу необходимо систематически отслеживать следующие основные показатели: содержание органического вещества (гумуса), показатель кислотности, содержание подвижного фосфора, содержание обменного калия.

При рассмотрении изменения содержания гумуса за период с 2012 г. на 4 площадках отмечено его критическое снижение. В отношении почвенной приуроченности такое изменение имело место на агроземах текстурно дифференцированных и агротемногумусовых подбелов, располагающихся на более выраженном рельефе, чем прочие наблюдаемые почвы. Согласно существующим критериям [9] почва имеет признаки деградации, когда содержание гумуса в пахотном горизонте снижается на $15 \%$ от исходного. В данном исследовании за точку отсчета приняты данные 2012 г. Выявлено, что на реперной площадке № 4 содержание гумуса в почве понизилось более чем на $15 \%$. На площадках № 2, 3 и 6 отмечено резкое его снижение на 9-13\%, когда гумусовое состояние свидетельствует о начале деградации почвы (таблица).

По результатам наблюдений на 11 реперных площадках за годы наблюдения 2012, 2014 и 2017 произошло снижение содержания гумуса в почвах пахотных угодий (рис. 2). Это является результатом нескольких причин, наиболее распространенных при производстве основных сельскохозяйственных культур на юге Дальнего Востока. К ним относятся: недостаточное внесение удобрений, выращивание сельскохозяйственных культур (преимущественно сои и кукурузы) как монокультуры, несоблюдение противоэрозионных агротехнических мероприятий.

При анализе причин такого значительного снижения содержания гумуса становится понятным, что оно произошло вследствие негативных явлений природного характера, усиленных антропогенным воздействием. Это ливневые дожди высокой интенсивности, выпавшие в конце июня - начале июля 2014 г. К причинам антропогенного характера относятся посевы сои и кукурузы с междурядьями вдоль склона, которые провоцируют смыв поверхностного слоя почвы (рис. 3).

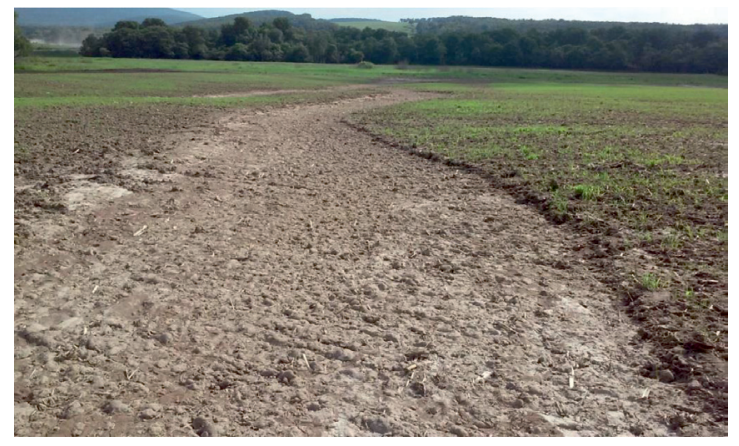

Рис. 3. Смыв почвы в районе реперной площуадки № 6 (посевы кукурузы), июнь 2014 г. 


\begin{tabular}{|c|c|c|c|c|c|c|c|c|c|c|c|c|c|c|c|c|}
\hline \multirow{8}{*}{ 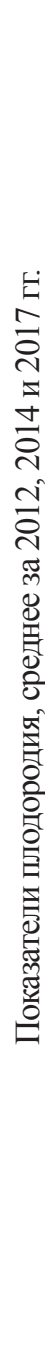 } & 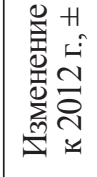 & $\vec{E}$ & $\underset{i}{i}$ & $\stackrel{m}{\rightarrow}$ & 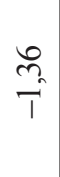 & $\stackrel{P}{i}$ & $\widehat{\Omega}$ & $\begin{array}{l}\hat{\sigma} \\
f\end{array}$ & $\stackrel{\infty}{\infty}$ & $\begin{array}{l}\stackrel{q}{+} \\
\underset{+}{+}\end{array}$ & $\begin{array}{l}\text { J } \\
\text { T }\end{array}$ & $\tilde{D}_{0}$ & $\stackrel{\tilde{m}}{i}$ & $\stackrel{m}{\rightarrow}$ & 8 & $\underset{-}{\infty}$ \\
\hline & 5 & ळે. & $\begin{array}{l}\tilde{\infty} \\
\tilde{n}\end{array}$ & 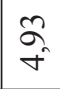 & $\begin{array}{l}\infty \\
\infty \\
+\end{array}$ & $\stackrel{m}{\sim}$ & 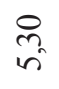 & $\begin{array}{l}\tilde{\gamma} \\
\dot{f}\end{array}$ & $\hat{n}$ & $\begin{array}{c}0 \\
i n\end{array}$ & $\stackrel{f}{f}$ & $\begin{array}{l}\hat{\sigma} \\
\dot{f}\end{array}$ & $\hat{n}$ & is & $\begin{array}{l}8 \\
8 \\
+\end{array}$ & $\begin{array}{l}8 \\
\text { in }\end{array}$ \\
\hline & 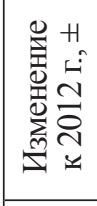 & $\begin{array}{l}\vec{n} \\
\hat{\varphi}\end{array}$ & $\begin{array}{l}\infty \\
\uparrow \\
\uparrow\end{array}$ & $\stackrel{2}{i}$ & $\stackrel{\mathscr{n}}{i}$ & $\stackrel{\infty}{\infty}$ & ণ্ & $\begin{array}{l}2 \\
\hat{1}\end{array}$ & $\stackrel{+}{n}$ & $\begin{array}{l} \pm \\
0 \\
0\end{array}$ & $\begin{array}{l}\text { ¿ } \\
\text { î }\end{array}$ & $\vec{i}$ & $\underset{T}{\stackrel{a}{T}}$ & $\left|\begin{array}{l}\infty \\
2 \\
1 \\
1\end{array}\right|$ & $\mid \begin{array}{c}\text { in } \\
\text { in }\end{array}$ & तิ \\
\hline & 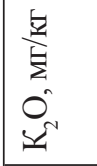 & $\begin{array}{c}\tilde{n} \\
\text { है }\end{array}$ & $\begin{array}{l}\tilde{\sigma} \\
\infty \\
0 \\
0\end{array}$ & 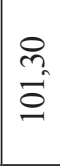 & ૂે & $\begin{array}{l}n \\
n^{\prime} \\
n \\
n\end{array}$ & $\begin{array}{l}n \\
\approx \\
\infty \\
\infty\end{array}$ & $\begin{array}{l}\text { in } \\
\text { ป } \\
\text { ปn }\end{array}$ & $\stackrel{n}{\approx}$ & $\begin{array}{l}\tilde{1} \\
\infty \\
\infty\end{array}$ & 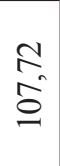 & 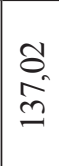 & $\stackrel{\Re}{\stackrel{\sigma}{a}}$ & $\begin{array}{c}\stackrel{B}{\circ} \\
\stackrel{n}{2}\end{array}$ & 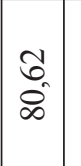 & $\begin{array}{l}\text { I } \\
\text { İ } \\
\text { I }\end{array}$ \\
\hline & 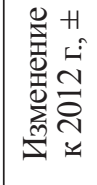 & $\frac{m}{0}$ & $\stackrel{\infty}{0}$ & $\frac{n}{0}$ & $\begin{array}{l}\overline{6} \\
0^{\circ}\end{array}$ & 足 & $\stackrel{+}{\Delta}$ & 8 & $\frac{n}{9}$ & $\begin{array}{l}\tilde{1} \\
\hat{i}\end{array}$ & $\begin{array}{l}8 \\
0 \\
0\end{array}$ & $\frac{\Delta}{0}$ & 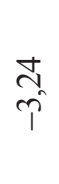 & $\stackrel{\infty}{\stackrel{1}{1}}$ & $\begin{array}{l}\hat{2} \\
\hat{\imath}\end{array}$ & $\begin{array}{l}0 \\
2 \\
0 \\
0\end{array}$ \\
\hline & $0^{n} \frac{1}{2}$ & $\stackrel{\Re}{\stackrel{\sim}{*}}$ & $\begin{array}{l}0 \\
n \\
n\end{array}$ & $\stackrel{m}{n}$ & $\overrightarrow{\widetilde{\sigma}}$ & $\begin{array}{l}\stackrel{\nabla}{ \pm} \\
\dot{d}\end{array}$ & $\begin{array}{l}\hat{n} \\
\hat{n}\end{array}$ & $\underset{\sim}{\mathbb{r}}$ & \begin{tabular}{l}
$\dddot{n}$ \\
\multirow{\sigma}{*}{}
\end{tabular} & 莒 & $\underset{\text { a }}{\forall}$ & $\stackrel{\cong}{\check{n}}$ & $\begin{array}{l}\circ \\
\infty_{0}^{\circ}\end{array}$ & $\begin{array}{l}3 \\
6 \\
6 \\
n\end{array}$ & $\stackrel{m}{\underset{\sigma}{*}}$ & $\begin{array}{l}\tilde{n} \\
\tilde{N}\end{array}$ \\
\hline & 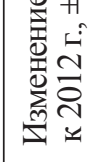 & $\begin{array}{l}\vec{\infty} \\
\dot{0}\end{array}$ & $\hat{\imath}$ & $\frac{\infty}{a}$ & Oे & $\frac{\infty}{\stackrel{\infty}{c}}$ & $\hat{i}$ & 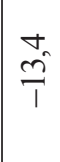 & $\stackrel{m}{n}$ & $\stackrel{\infty}{\stackrel{\infty}{\rightarrow}}$ & $\begin{array}{l}0 \\
\text { nn } \\
\text { in }\end{array}$ & $\stackrel{\infty}{\stackrel{i}{i}}$ & 8 & $\begin{array}{l}\infty \\
\infty \\
\hat{p}\end{array}$ & $\begin{array}{l}0 \\
\hat{\sigma}_{0}\end{array}$ & m. \\
\hline & 号 & 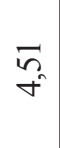 & 点 & $\begin{array}{l}\infty \\
\infty \\
i\end{array}$ & $\frac{n}{m}$ & $\underset{i}{\stackrel{8}{0}}$ & 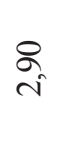 & $\begin{array}{l}n \\
i \\
i\end{array}$ & $\stackrel{8}{-}$ & $\begin{array}{l}\stackrel{8}{0} \\
\Re\end{array}$ & 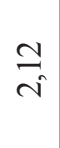 & $\underset{+}{\stackrel{t}{f}}$ & $\begin{array}{l}\infty \\
\stackrel{\infty}{n}\end{array}$ & $\underset{r}{8}$ & $\stackrel{ \pm}{\stackrel{ \pm}{m}}$ & $\underset{\substack{0 \\
0}}{0}$ \\
\hline & 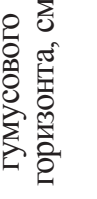 & $\frac{\pi}{d}$ & $\stackrel{\vec{J}}{0}$ & & $\frac{\infty}{1}$ & $\hat{\tilde{\delta}}$ & ঠి & $\hat{\jmath}$ & $\hat{\widehat{\jmath}}$ & $\tilde{\hat{\jmath}}$ & $\stackrel{\imath}{\tilde{0}}$ & $\tilde{\tilde{\delta}}$ & ठิ & సิ & ते & రి \\
\hline $\begin{array}{l}\overrightarrow{\hat{A}} \\
\text { 兽 }\end{array}$ & & 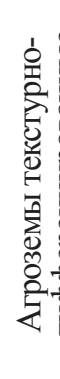 & & & & & & 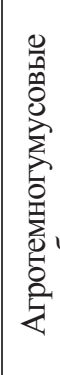 & & & & & & 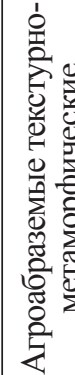 & 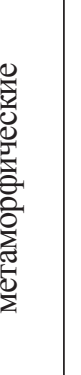 & 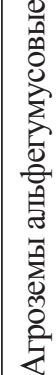 \\
\hline 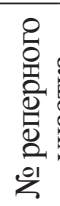 & हु & - & $m$ & 0 & $r$ & 으 & 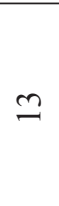 & N & $\nabla$ & $\infty$ & $a$ & $=$ & $\Xi$ & $\simeq$ & in & $\because$ \\
\hline
\end{tabular}


Содержание фосфора в почве является одним из самых сложных и динамичных показателей, который зависит от ряда факторов природной среды. Почвы юга Дальнего Востока в своем естественном состоянии имеют низкое содержание подвижного фосфора при его повышенной валовой форме, что было доказано многими исследованиями $[1,10,11]$. В 1960-е гг. более $80 \%$ обследованной территории Приморского края относили к слабо обеспеченной подвижным фосфором. Однако в последующие годы, когда проходил так называемый период химизации сельскохозяйственных почв, эту ситуацию искусственно изменили. В почву были внесены в значительном объеме минеральные удобрения с большим содержанием фосфора, что способствовало улучшению фосфатного режима задействованных в этом процессе почв. В то же время внесение фосфорсодержащих удобрений не везде проводилось с одинаковой интенсивностью. В дальнейшем это стало причиной неравномерности и резких различий в обеспеченности почв Приморского края подвижными формами фосфора. Поэтому одни пахотные угодья имеют признаки избытка подвижных форм фосфора, другие им не обеспечены [11].

Наблюдения на реперных площадках показали значительные различия по содержанию подвижного фосфора в пахотном слое (рис. 4). Это может быть следствием значительных антропогенных нагрузок 1960-1990-х гг. [10], при которых внесение фосфорсодержащих минеральных удобре- ний не всегда контролировалось должным образом. Поэтому в части пахотных почв юга Дальнего Востока до сих пор наблюдается повышенное содержание фосфора, даже при умеренном его внесении действующими на этих землях производителями сельскохозяйственной продукции.

Калий - один из элементов минерального питания растений, который является основным по уровню потребления сельскохозяйственными культурами. Он влияет на увеличение устойчивости растений к стрессовым факторам окружающей среды, таким как засуха, переувлажнение, понижение температуры в период вегетации [12]. Использование почв продолжительный период экстенсивным способом повлияло на изменение содержания калия. Современные обрабатываемые земли отличаются по содержанию обменного калия вне зависимости от типа почв, нередко наблюдается значительное варьирование этого элемента в пределах одного почвенного типа [13]. Поэтому оперативный мониторинг содержания обменного калия важен для контроля плодородия обрабатываемых земель. Определение содержания обменной формы калия в почве служит основой для расчета доз минеральных удобрений, оптимальные величины которых определены на основе экспериментов [14]. Содержание калия в почве более 100 мг/кг является высоким, 50-100 мг/кг - средним, менее 50 мг/кг - низким [1, 10]. Согласно этой градации содержание обменного калия в почвах наблюдаемых реперных площадок среднее и высокое (рис. 5).

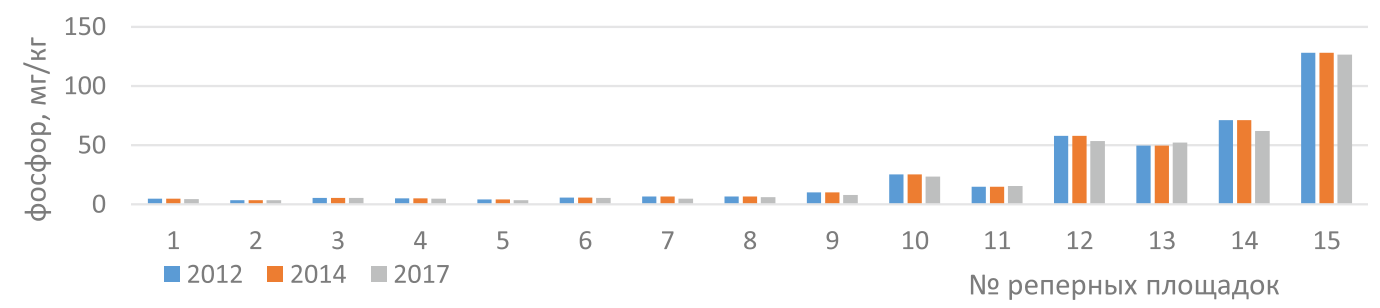

Рис. 4. Содержание подвижного фосфора (мг/кг) на реперных площзадках в 2012, 2014 и 2017 г2.

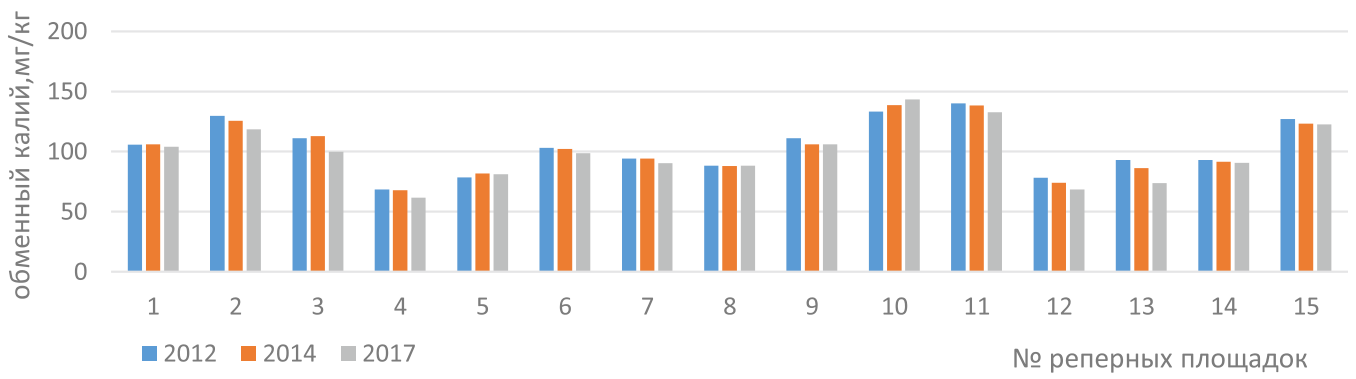

Рис. 5. Содержание обменного калия (мг/кг) на реперных площуадках в 2012, 2014 и 2017 z2. 


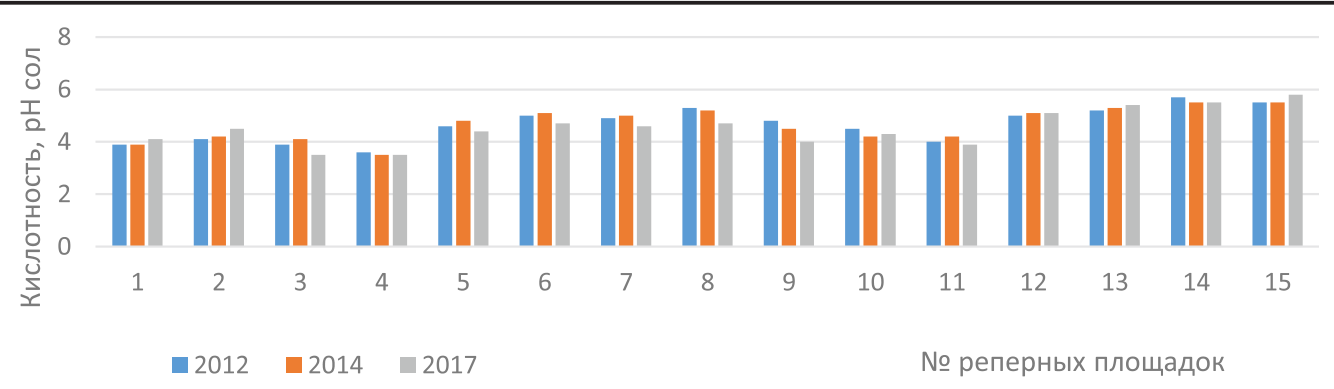

Рис. 6. Кислотность почв ( ( $_{\text {coл }}$ ) на реперных площуадках в 2012, 2014 и 201722.

Кислотность почв служит показателем доступности элементов питания для растений. Изменение этого показателя за период наблюдения произошло как в сторону снижения на $1-4 \%$, так и повышения на $1-7 \%$ (рис. 6).

\section{Выводы}

1. Основные параметры почвенного плодородия при интенсивном использовании почв ухудшаются в среднем на $4 \%$ по гумусу, на 2\% по калию, около $1 \%$ по кислотности. Содержание фосфора снижается в меньшей степени.

2. Мониторинг почв на основе реперных площадок позволяет оперативно регулировать поступление основных элементов питания в почву и может стать основой для получения исходных и контрольных данных о плодородии почв отдельных земельных участков.

\section{Список литературы / References}

1. Синельников Э.П. Оптимизация свойств и режимов периодически переувлажняемых почв / Под ред. Ознобихина. Уссурийск: ДВО ДОП, 2000. 296 с.

Sinelnikov E.P. Optimization of properties and regimes of periodically wetted soils / Pod red. Oznobixina. Ussurijsk: DVO DOP, 2000. 296 p. (in Russian).

2. Блохин В.Д., Моисеенко А.А., Ступин В.М. Научные основы земледелия на Дальнем Востоке России. Владивосток: Дальнаука, 2011. 216 c.

Blohin V.D., Moiseenko A.A., Stupin V.M. Scientific foundations of agriculture in the Far East of Russia. Vladivostok: Dal'nauka, 2011.216 p. (in Russian).

3. Суржик М.M., Ознобихин В.И., Чеканникова Т.А., Черняк Д.М. К оценке плодородия почв пашенных земель юга российского Дальнего Востока // Успехи современного естествознания. 2016. № 12-1. С. 105-109.

Surzhik M.M., Oznobikhin V.I., Chekannikova T.A., Chernjak D.M. To the assessment of soil fertility of the arable lands of the South of the Russian Far East // Advances in current natural sciences. 2016. № 12-1. P. 105-109 (in Russian).

4. Суржик M.M. Зависимость продуктивности кормового севооборота от различных систем удобрений в условиях Приморского края // Вестник Красноярского государственного аграрного университета. 2011. № 9 (60). С. 72-76.

Surzhik M.M. The dependence of the productivity of fodder crop rotation on various fertilizer systems in Primorye region // Vestnik Krasnoyarskogo gosudarstvennogo agrarnogo universiteta. 2011. № 9 (60). P. $72-76$ (in Russian).

5. Мухина Н.В., Ознобихин В.И. Мониторинг агрогенных почв. Уссурийск: Изд. ФГБОУ ВПО «Приморская ГСХА», 2014. 124 с.
Mukhina N.V., Oznobikhin V.I. Monitoring of the agrogenis soils. Ussurijsk: Izd. FGBOU VPO «Primorskaya GSXA», 2014. 124 p. (in Russian).

6. ГОСТ 26213-91. Почвы. Методы определения органического вещества. [Электронный ресурс]. URL: http://docs. cntd.ru/document/1200023481 (дата обращения: 20.02.2020).

7. ГОСТ Р 54650-2011. Почвы. Определение подвижных соединений фосфора и калия по методу Кирсанова в модификации ЦИНАО. URL: http://docs.cntd.ru/document/ gost-r-54650-2011 (дата обращения: 20.02.2020).

8. ГОСТ 26483-85. Почвы. Приготовление солевой вытяжки и определение ее $\mathrm{pH}$ по методу ЦИНАО. URL: http://docs. cntd.ru/document/gost-26483-85 (дата обращения: 20.02.2020).

9. Постановление Правительства РФ от 22 июля 2011 г. № 612 «Об утверждении критериев существенного снижения плодородия земель сельскохозяйственного назначения. [Электронный ресурс]. URL: http://base.garant. $\mathrm{ru} / 12188226$ (дата обращения: 20.02.2020).

Decree of the Government of the Russian Federation of July 22, 2011 No. 612 «On the approval of criteria for a significant decrease in the fertility of agricultural land». [Electronic resource]. URL: http://base.garant.ru/12188226 (date of access: 20.02.2020) (in Russian).

10. Синельников Э.П., Слабко Ю.И. Агрогенензис почв Приморья / Под ред. академ. А.К. Чайка. М.: ГНУ ВНИИА, 2005. $280 \mathrm{c}$.

Sinelnikov E.P., Slabko Yu.I. Agrogenesis if Primorye soils / Pod red. akadem. A.K. Chajka. M.: GNU VNIIA, 2005. 280 p. (in Russian).

11. Григорьева Л.Г., Слабко Ю.И., Синельников Э.П. Оценка фосфатного состояния пахотных почв Приморья // Плодородие. 2007. № 3 (36). С. 2-4.

Grigorjeva L.G., Slabko Yu.I., Sinelnikov E.P. Assessment of the phosphate state of arable land in Primorye // Plodorodie. 2007. № 3 (36). P. 2-4 (in Russian).

12. Афанасьев Р.А., Мерзлая Г.Е. Содержание подвижного калия в почвах при длительном применении удобрений // Агрохимия. 2018. № 6. С. 5-11.

Afanasjev R.A., Merzlaya G.E. Content of exchangeable potassium in soils under long-term fertilization // Agrohimiya. 2018. № 6. P. 5-11 (in Russian).

13. Жарикова Е.А., Костенков Н.М. Потенциальная буферная способность почв в отношении калия при проведении агроэкологического мониторинга // Плодородие. 2011. № 2. C. 48-49.

Zharikova E.A., Kostenkov N.M. Potential soil buffering capacity for potassium during agroecological monitoring // Plodorodie. 2011. № 2. P. 48-49 (in Russian).

14. Сакара Н.А., Колодкин В.Г., Тарасова Т.С., Ознобихин В.И., Кольев Н.В. Влияние хлористого калия на урожай и качество продукции в овощных севооборотах на окультуренных почвах юга Приморья // Вестник ДВО РАН. 2018. № 3. C. 64-68.

Sakara N.A., Kolodkin V.G., Tarasova T.S., Oznobihin V.I., Koljev N.V. Effect of potassium chloride on yield and product quality in vegetable crop rotation on cultivated soils of southern Primorye // Vestnik DVO RAN. 2018. № 3. P. 64-68 (in Russian). 